\title{
Statyba
}

\section{REFRACTORY GUNITE AND REFRACTORY CONCRETES COMPACTED USING VARIOUS METHODS}

\section{S. Goberis \& V. Antonovič}

To cite this article: S. Goberis \& V. Antonovič (1996) REFRACTORY GUNITE AND

REFRACTORY CONCRETES COMPACTED USING VARIOUS METHODS, Statyba, 2:7, 24-29, DOI: $10.1080 / 13921525.1996 .10531651$

To link to this article: https://doi.org/10.1080/13921525.1996.10531651

曲 Published online: 26 Jul 2012.

Submit your article to this journal $₫$

Џll Article views: 164 


\section{KAITRAI ATSPARUS TORKRETBETONIS IR KITAIS BŪDAIS SUTANKINTI BETONAI}

\section{S.Goberis, V.Antonovic}

\section{1. İvadas}

Terminas "torkretavimas" yra kilęs iš lotynų kalbos ir reiškia "tinko sutirštinimą". Statyboje torkretavimu vadinamas betono ar skiedinio mišinio (torkretbetonio mišinio) užpurškimas (suslègtu oru) ant dengiamojo paviršiaus.

Siluminiuose agregatuose torkretavimas pirmiausia buvo naudojamas remontuoti pramoniniy krosniy ir garo katilų futeruotę. Šs metodas pasirodè esąs efektyviausias ir naxiausias futeruojant chemijos ir naftos pramonès aparatus [1].

Labai svarbu, kad futeravimas torkreto būdu atliekamas mechanizuotai, todèl sumažèja ranku darbo, sutrumpéja darbo laikas, didesnis jo našumas lyginant su futeravimu ugniai atspariais gaminiais. Torkretavimo būdu pagamintoje futeruotèje daug mažiau siūlių, t.y. eksploatavimo metu labiausiai pažeidžiamų vietų.

Nors kaitrai atsparus torkretbetonis jau daug mety plačiai naudojamas užsienio šalyse, taip pat futeruojant cemento krosnis [2], Lietuvoje krosnims futeruoti iki siol mažai taikomas. Tą lèmè gautos iš Rusijos netobulos torkretavimo mašinos ir tai, kad nebuvo centralizuotos torkretbetonio mišinių, ipakuoty maišuose, gamybos. Dèl šių priežasčiu buvo sunku pagaminti aukštos kokybès futeruotę torkretavimo būdu.

Šio darbo tikslas - sukurti kaitrai atsparius torkretbetonius iš turimy vietinių medžiagu ir gamybos atlieku, nustatyti pagrindines betony fizikines bei mechanines charakteristikas, išsiaiškinti kaitrai atsparaus betono struktūros formavimo skirtumus sutankinant $\mathrm{ji}$ ivairiais metodais. Be to, reikejjo issisavinti torkretavimo technologiją, Termoizoliacijos institute organizuoti laboratorijos kontroliuojamą centralizuotą mišiniy gamybą, įsisavinti Šveicarijos firmos "Meyco
Piccola" nepertraukiamo veikimo irengini ir idiegti sukurtus torkretbetonius pramonèje.

Kuriant savos gamybos torkretbetonius, naudoti lengvieji (keramzitas, vermikulitas, diatomitas, lengvasis šamotas) ir sunkieji (samotas) užpildai, bei rišiklis aliuminatinis cementas. Dispersinis komponentas pagaminamas malant trupintas samoto plytu atliekas rutuliniame malūne.

\section{Eksperimenty metodika}

Tyrimuose naudoti trys betono sutankinimo metodai: torkretavimas, vibravimas, plükimas.

Torkretavimo metodas. Eksperimentuose bandiniams pagaminti buvo naudojama firmos "Meyco Piccola" torkretavimo mašina, apibūdinama šiais parametrais: maksimalus našumas $-3,3 \mathrm{~m}^{3} / \mathrm{h}$, mišinio padavimo nuotolis - iki $500 \mathrm{~m}$, mišnio padavimo aukštis - iki $100 \mathrm{~m}$, oro spaudimas - 4-6 at., oro kiekis $3-8 \mathrm{~m}^{3} / \mathrm{min}$., masè - $350 \mathrm{~kg}$ ( $1 \mathrm{pav}$.).

Mašina su pastoviai besisukanciu rotoriumi dozuoja mišini mažomis porcijomis ị padavimo vamzdị. Rotorius gali būti su skirtingos formos maitinimo kameromis, ir varomas dvieju greičį elektros varikliu. Tokiu būdu mašina pritaikoma sunkiesiems ir lengviesiems torkretbetonio misiniams.

Viršutinis ir apatinis rotoriaus paviršiai užsandarinti specialiais guminiais diskais, kurie užtikrina tolygu mišinio maitinimą ir neleidžia jam segreguotis. Kad geriau susimaišytų mišinys su vandeniu, torkretbetonio srovè nukreipiama guminiu antgaliu su briaunomis. Šio tipo mašina užtikrina nepertraukiamą pusiau sauso torkretavimo procesą, yra lengvai valdoma.

Sukurtų sudėcių torkretbetonių sausi mišiniai (po 100 litru) buvo gaminami 300 litru talpos pramoninèje maišyklèje, o komponentai dozuojami matavimo indais. 


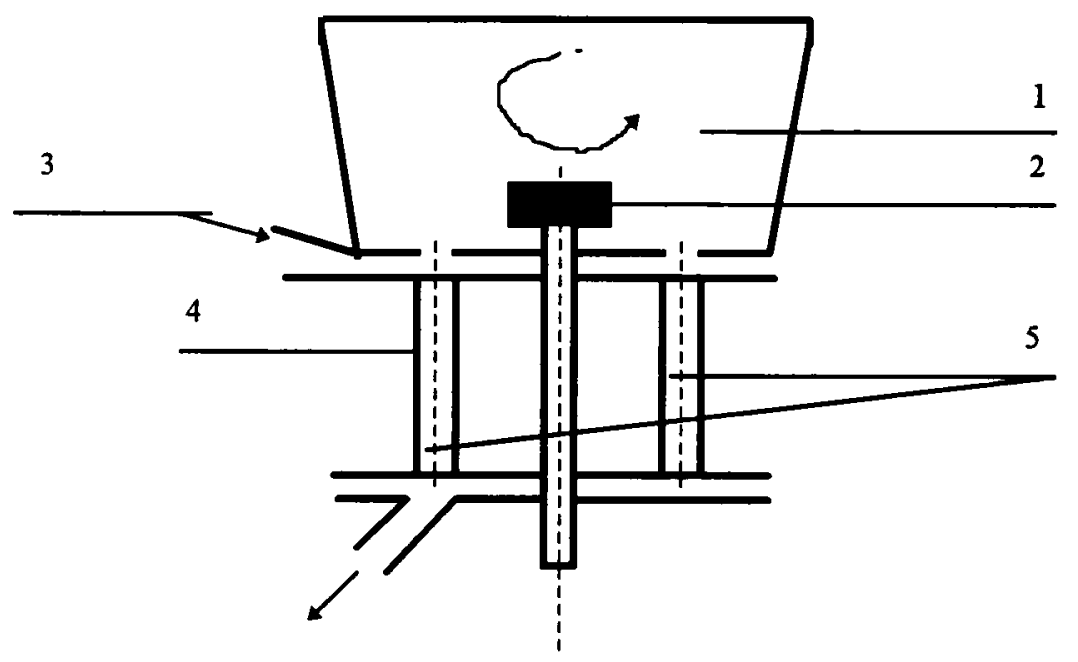

1 pav. Torkretavimo mašinos schema: 1 - bunkeris; 2 - maišytuvas; 3 - oro kanalas; 4 - maitinimo būgnas (rotorius ); 5 - dozavimo kanalai

Fig. 1. Scheme of gunning machine: 1 - hopper; 2 - mixer; 3 - air duct; 4 - rotor; 5 - batcher ducts

Eksperimento metu buvo palaikomas $1,8-2,0$ MPa. oro slègis torkretavimo mašinos mišinio dozavimo kanale, torkretbetonio srovè nukreipiama staciu kampu i torkretavimo pavirsiu, o atstumas tarp jo ir guminio antgalio - nuo $30 \mathrm{iki} 50 \mathrm{~cm}$, kaip rekomenduojama [3].

Eksperimentams paruoštas torkretavimo stendas - metalinè $100 \times 100 \mathrm{~cm}$ dydžio sienelè su metaliniais rèmais. Prie dengiamos torkretbetoniu sienelés $20 \mathrm{~cm}$ žingsniu privirinti specialūs armavimo elementai.

Futeruotès fragmento pagaminimo torkretavimo stende tikslas - įvertinti torkretbetoniu atšokas. Todèl $\mathfrak{i}$ torkretavimo mašiną buvo tiekiama po 50 litrų torkretbetonio sausų mišinių. Pagaminus futeruotès fragmentą, atšokos surenkamos, džiovinamos ir sužinomas jų kiekis.

Nustatyti torkretbetoniy fizikinems ir mechaninèms charakteristikoms pagaminami $40 \times 40 \times 7 \mathrm{~cm}$ dydžio bandiniai. Forma bandiniui pagaminti buvo statoma vertikaliai. Sukietejus torkretbetoniui, deimantiniu disku iš bandinio išpjauti $7 \times 7 \times 7 \mathrm{~cm}$ dydžio kubai, kurie panaudoti tolesniems tyrimams.

Vibravimo metodas. $7 \times 7 \times 7 \mathrm{~cm}$ dydžio kubai buvo gaminami metalinèse formose. Gerai (rankiniu būdu) su vandeniu sumaišyta betono mase klojama i formą ir 2 minutes vibruojama ( $50 \mathrm{~Hz}$ dažnumu) ant vibrostalo. Kubų paviršius užlyginamas metaline juosta.
Plūkimo metodas. Naudojamos tos pacios $7,07 \mathrm{x}$ $7,07 \times 7,07 \mathrm{~cm}$ dydžio metalinès formos bandiniams gaminti. Paruošta betono mase klojama i formą dalimis (po $1 / \beta$ formos aukšcio) ir plūkiama $1 \mathrm{~kg}$ svorio, $8 \mathrm{~cm}^{2}$ skersmens metaliniu strypu. Plūkiama rankiniu būdu, nestipriais smūgiais tol, kol betono masès tūris formoje nebesikeixia. Kubų paviršius užlyginamas metaline juosta.

Ivairiais būdais sutankinti betono bandiniai kietèjo 7 paras, po to buvo džiovinami $110^{\circ} \mathrm{C}$ ir degami $800^{\circ} \mathrm{C}$ bei $1100^{\circ} \mathrm{C}$ temperatūroje, vèliau nustatomos šios betonų charakteristikos: tankis, stipris gniuždant, susitraukimas ir ultragarso impulso greitis.

\section{Betony tyrimo rezultatai}

Sukurtos penkios torkretbetonio sudetys, kuriose aliuminatinio cemento kiekis buvo vienodas, o kiti komponentai parenkami taip, kad sausų mišiniu supiltinis tankis keistųsi nuo didžiausio iki minimalaus $\left(1500-850 \mathrm{~kg} / \mathrm{m}^{3}\right)$. Kartu ir sukietejjusio torkretbetonio tankis kito nuo $1890 \mathrm{iki} 1200 \mathrm{~kg} / \mathrm{m}^{3}$. Maksimalaus užpildų grūdo dydis $-0,5 \mathrm{~cm}$.

Isisavinant torkretavimo technologiją stende, ịvertinti atšoku nuostoliai bei ju charakteristikos. Gauti rezultatai rodo, kad atšokų kiekis priklauso nuo torkretbetonio markès ir svyruoja nuo $10 \mathrm{iki}$ $18 \%$. Atšokų supiltinis tankis lengvesniuose torkretbetoniuose mažesnis, nes, kaip parodè tyrimai, daugiau atšoka lengvų užpildų dalelès (žr. 1 lent.). 
1 lentelè. Torkretbetoniy tyrimo rezultatai

Table 1. Results of refractory gunite investigations

\begin{tabular}{|c|c|c|c|c|c|}
\hline \multirow[b]{2}{*}{ Betono charakteristikos } & \multicolumn{5}{|c|}{ Betono markè } \\
\hline & A.S.S-5 & AS. VSS-5 & 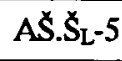 & AS. $V_{S} S_{L}-5$ & $A \stackrel{x}{A} \cdot V_{g} D \breve{S}_{L}-5$ \\
\hline Betono sausu mišinių supiltinis tankis, $\mathrm{kg} / \mathrm{m}^{3}$ & 1500 & 1150 & 1050 & 940 & 850 \\
\hline Atšoka, $\%$ & 12 & 17.6 & 16.6 & 17.6 & 9.8 \\
\hline Atšokos supiltinis tankis, $\mathrm{kg} / \mathrm{m}^{3}$ & 1070 & 970 & 950 & 780 & 730 \\
\hline Tankis po kietėjimo, $\mathbf{k g} / \mathrm{m}^{3}$ & 1890 & 1770 & 1520 & 1600 & 1260 \\
\hline Susitraukimas, $\%$ po $800^{\circ} \mathrm{C}$ & 1.06 & 0.27 & 1.12 & 1.18 & 0.9 \\
\hline $\begin{array}{l}\text { Maksimali panaudojimo } \\
\text { temperatūra, }{ }^{\circ} \mathrm{C}\end{array}$ & 1300 & 1150 & 1200 & 1150 & 1000 \\
\hline
\end{tabular}

Torkretbetoniu deformaciniu savybiy tyrimai parodé, kad pagal mišinių supiltinị tankị ir užpildų charakteristikas bandinių susitraukimas po degimo $800^{\circ} \mathrm{C}$ temperatūroje svyruoja $0,27-1,18 \%$ ribose.

Nustatyta, kad torkretuojant metalo paviršiu, betono struktūra nėra homogeniłka: prie paviršiaus susidaro 3-5 mm storio dispersinių dalelių skiedinio sluoksnis, o toliau - normali betono struktūra. Kaitinant dèl skirtingų sių struktūrų deformacinių savybiu kartais atsiskiria sluoksniai. Norint $\varsigma_{i}$ neigiamą reiškinị pašalinti, praktikoje būtina didelị dèmesi skirti kaitrai atsparaus torkretbetonio armavimo darbams.

Eksperimenty metu nustatytas vandens kiekio poreikis, kuris tiek plūkiant, tiek vibruojant tos pačios markès betoną išliko praktiškai vienodas. Teorinis vandens ir cemento santykis betonuose turi būti $10-15 \%$. Gaminant bandinius torkretavimo būdu nebuvo galimybès sužinoti tiekiamo ị mišinị vandens kiekio, todèl apskaičiuoti dehidratacijos proceso nuostoliai džiovinant $110^{\circ} \mathrm{C}$ ir kaitinant $800^{\circ} \mathrm{C}$ temperatūroje ìvairiais būdais pagamintus bandinius. Rezultatai rodo, kad torkretavimo būdu pagaminti betono bandiniai bet kuriuo atveju džiovinimo metu praranda mažiau masès, nei vibruoti ar plūkti bandiniai. Iš to galima daryti išvadą, kad vandens poreikis torkretbetoniui yra daug mažesnis. Betonas, pagamintas iš sauso, maksimalaus supiltinio tankio mišinio džiovinant ir kaitinant prarado daug mažiau masès nei lengvesni betonai.

Reikia pažymèti, kad vandens poreikis gaminant vibruotus ir plūktus bandinius gerokai viršija masès nuostolius po kaitinimo iki $800^{\circ} \mathrm{C}$. Tai rodo, kad cemento hidratacijos metu nemaža vandens išgaruoja. Kuo lengvesnis betonas, tuo didesnè dalis vandens išgaruoja (kai sauso mixinio supiltinis tankis $850 \mathrm{~kg} / \mathrm{m}^{3}$, betono bandiniai hidratacijos metu prarado daugiau nei $50 \%$ vandens; 2 pav.).

Buvo i̇domu palyginti îvairiais būdais sutankintu kaitrai atsparių betonų stiprumo charakteristikas (3 pav.).

Nustatyta bendra stiprio gniuždant mažėjimo tendencija, padidinus apdorojimo temperatūrą iki $800^{\circ} \mathrm{C}$ ir $1100^{\circ} \mathrm{C}$. Mažèjant betono sauso mišnio supiltiniam tankiui nuo 1500 iki $850 \mathrm{~kg} / \mathrm{m}^{3}$, stiprumo charakteristikos mažèja. Tačiau esant dideliam supiltiniam tankiui, vibravimo ir plūkimo būdais pagaminti bandiniai yra daug stipresni nei torkretbetonio bandiniai. Kai supiltinis tankis mažesnis, visais atvejais torkretbetonio stiprumo charakteristikos esti didesnès, nes lengvesni betono komponentai yra geriau sutankinami torkretavimo energija, nei vibruojant ar plūkiant. Tai patvirtina ir ultragarso impulso greičio matavimo rezultatai (4 pav.). 


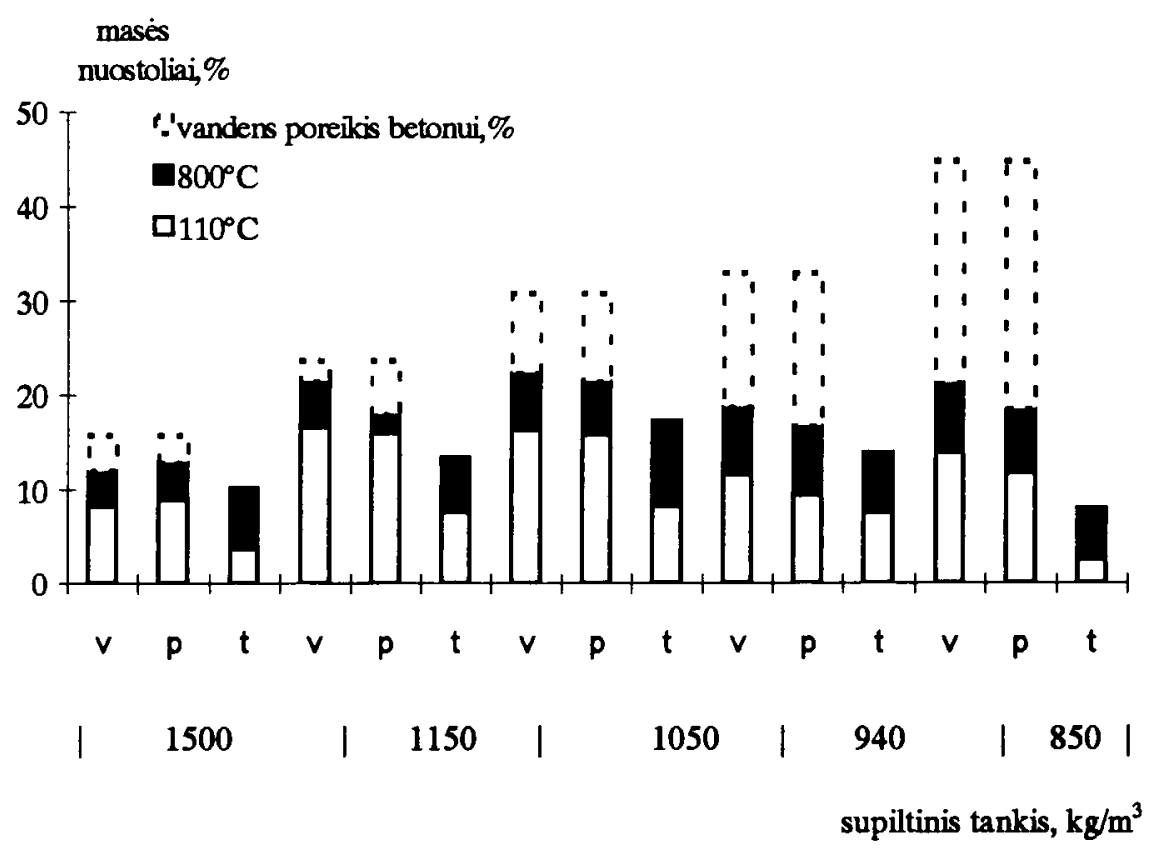

2 pav. Masès nuostolių priklausomybè nuo kaitinimo temperatūros ir nuo ivairiais būdais sutankinto betono sauso mišnio supiltinio tankio: $v$ - vibravimas, $p$ - plūkimas, $t$ - torkretavimas.

Fig. 2. Loss of gunite mass dependence on firing temperature and dry mixture bulk density: $v$ - vibration; $\mathrm{p}$ - ramming; $\mathrm{t}$ - gunning

Reikia pažymèti, kad plükimo būdu pagaminti bandiniai visais atvejais charakterizuojami mažiausiais stiprio dydžiais. Matyt, šis metodas taikytinas tik labai standiems ir sunkiems betonams.

\section{Torkretbetoniu diegimas pramonëje}

\section{Šveicarijos firmos "Meyco Piccola"} torkretavimo mašinos pagalba sukurti betonai idiegti pramoneje. $A B$ "Mažeikiu nafta" pagaminta futeruotè $27 \mathrm{~m}$ ilgio ir $3 \mathrm{~m}$ skersmens dūmtraukiui. Prieš torkretavimą prie dūmtraukio korpuso buvo privirinti apie $70 \mathrm{~mm}$ ilgio armavimo elementai. Dümtraukio futeruotèje panaudoti dvieju markių AŠ. $V_{S} \breve{S}_{L}-5$ bei AŠ. $V_{S} \grave{S}-5 . K-5$ Termoizoliacijos institute pagaminti betonai. Nurodytiems betonams buvo keliamas reikalavimas, $\mathrm{kad} 1 \mathrm{~m}^{2} 100 \mathrm{~mm}$ storio futeruotés svertų ne daugiau $70 \mathrm{~kg}$. Atšokų kiekis torkretavimo metu neviršijo $15 \%$. Vilniaus termofikacinèje elektrinèje Nr.2 katilo PTVM N3 sienų futeruotè pagaminta iš kaitrai atsparaus

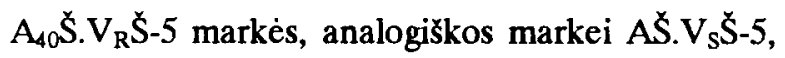
betono.

Šiuo metodu pagamintos šilumos agregatu elementy futeruotès būklè bus stebima eksploata- cijos metu ir po tam tikro periodo bus ivertinti joje panaudoti torkretbetoniai.

\section{IŠvados}

Lyginant kaitrai atspariy betony, pagaminty ivairiais sutankinimo metodais, charakteristikas nustatyta, kad torkretavimo būdas pasižymi mažesniu vandens poreikiu negu vibravimas ar plūkimas.

Visais bũdais pagamintų betonų stiprumo charakteristikos mažèja didinant bandiniu apdorojimo temparatūrą. Sutankinimo būdas daro ženklią ịtaką betonų stipriui gniuždant: beveik visais atvejais aiški tendencija didesnio stiprio torkretbetonio negu vibruoto ar plūkto betono visame apdorojimo temperatūrų intervale. Tik esant maksimaliam betono sauso mišinio supiltiniam tankiui vibravimu ir plūkimu pagaminami stipresni betonai.

Ultragarso greičio matavimų rezultatai patvirtina, kad torkretvimo būdu pagaminti kaitrai atspanūs betonai pasižymi tankesne struktūra, negu vibruoti ar plūkti.

Sukurti betonai panaudoti $A B$ "Mažeikių nafta" siluminių agregatų futeravimui. 

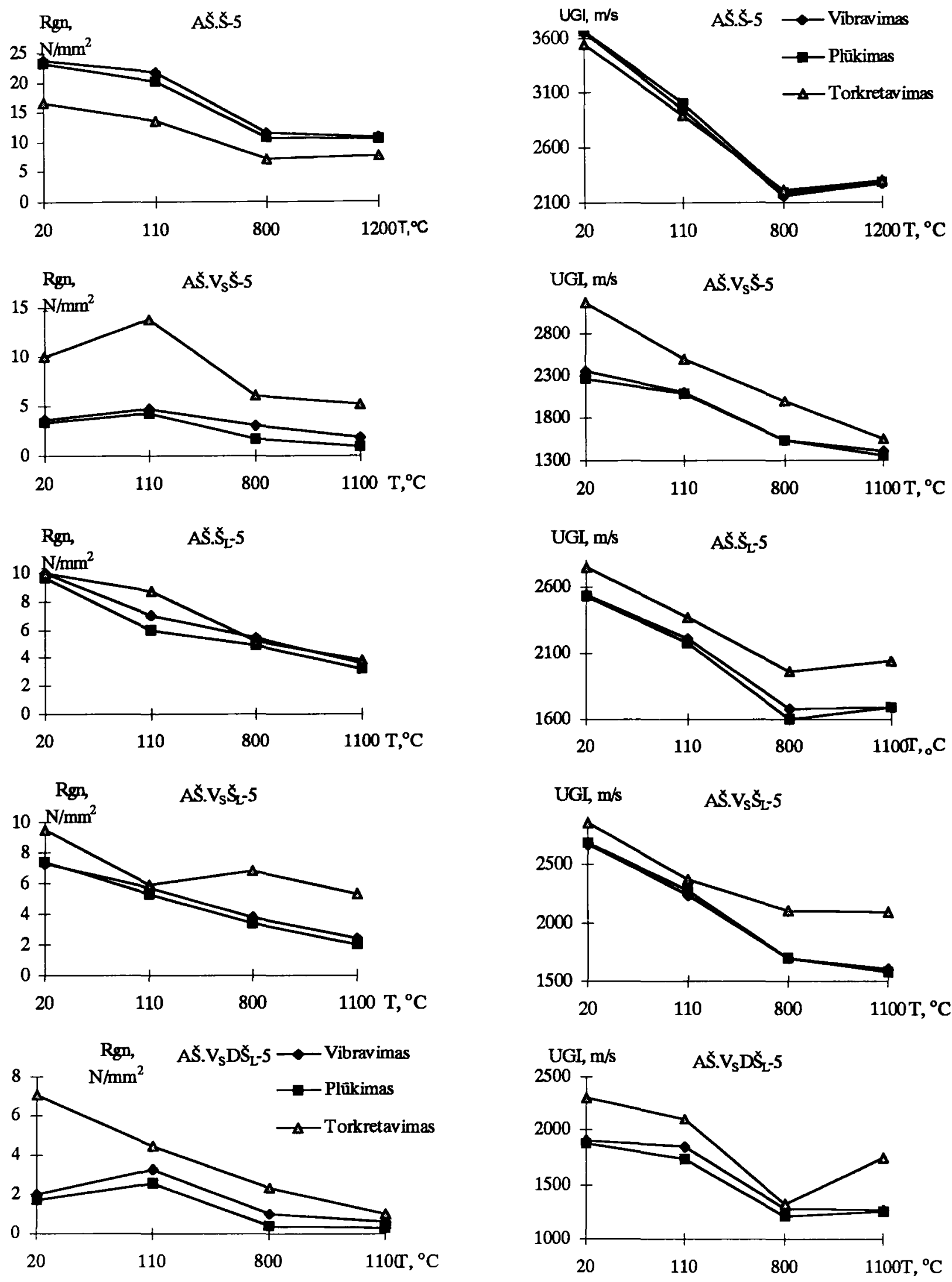

3 pav. Stiprio gniuždant priklausomybè nuo apdorojimo temperatūros

Fig. 3. Cold crushing strength dependence on firing temperature

4 pav. Ultragarso greið̌io priklausomybè nuo apdorojimo temperatūros

Fig. 4. Ultrasonic impulse velocity dependence on firing temperature 


\section{Literatūra}

1. И.К. Позднякова. Составы, способы и устройства для торкретирования тепловых агрегатов. М. ЦБТНТИ Минмонтажспецстроя СССР Экспресс-информация, Вып.5, 1979. 16 с.

2. H.K. Fleck Casting of satellite cooler using refractory bricks and castables // International Cement Review. September 1991, p.42-46.

3. АП.Агурин, А.С.Денисов, А.С.Лукашевич. Торкретирование тепловых агрегатов. М.: Стройиздат, 1989. 144 с.

Iteikta 19961121

\section{REFRACTORY GUNITE AND REFRACTORY CONCRETES COMPACTED USING VARIOUS METHODS}

\section{S.Goberis, V.Antonovie}

S u m m a r y

The aim of these investigations is to develop refractory gunite using local and waste materials available in Lithuania, to investigate its physical and mechanical properties and compare them with the same density and composition concrete compacted by vibration and ramming methods.

In this work light (vermiculite, expanded fire clay, diatomite) and heavy (shamotte) aggregates with aluminium cement as binding material were used.

The concrete samples $(7 \times 7 \times 7 \mathrm{~cm})$ were fired at various temperatures from $20^{\circ} \mathrm{C}$ to $1100^{\circ} \mathrm{C}$.
Five types of refractory gunites with different dry mixtures having a bulk density from 850 to $1500 \mathrm{~kg} / \mathrm{m}^{3}$ have been developed. It was shown that concrete cold crushing strength depends on dry mixture bulk density and firing temperature: heavy concrete samples compacted by vibration and ramming methods are stronger, while light concrete samples made by gunning are better. The influence of temperature decreases the strength characteristics, which was confirmed by ultrasonic impulse velocity measurement results. An estimation of water requirements for concrete sample production various compacting methods is given. It was found that gunite water requirements are substantially lower than for rammed or vibrated concrete.

Newly developed refractory gunite was used in furnaces as lining in an exhaust flue at Mažeikiai Oil Refinery.

Stasys GOBERIS. Doctor of technical sciences. Head of Institute Termoizoliacija Laboratory. Institute Termoizoliacija, 28 Linkmeny St, 2600 Vilnius.

A graduate of Ural Polytechnical Institute, 1954, metallurgical engineer. Doctor's degree in 1966 at Concrete and Reinforced Concrete Institute (NIIGB, Moscow); thesis about technology of refractory concretes. Author of 217 papers, 23 inventions. Research interests: refractory materials, their application in furnaces.

Valentinas ANTONOVIČ. Vilnius Gediminas Technical University, Dept of Building Materials. Engineer of Institute Termoizoliacija, 28 Linkmenų St, 2600 Vilnius.

A graduate of Vilnius Civil Engineering Institute (now VGTU), 1989, mechanical engineer. Since 1994 a doctoral student at VGTU. Co-author of 10 publications. Research interests: new refractory concretes and their technologies. 